\title{
Using Mobile Device to Increase Student Academic Outcomes in Qatar
}

\author{
Ramzi Nasser \\ Department of Educational Sciences, Qatar University, Doha, Qatar \\ Email: ramzin@qu.edu.qa
}

Received September 2013

\begin{abstract}
The purpose of this study was to investigate the impact and use of mobile learning tools out of school work. The study determined whether the school assignment prompts has improved student outcome in a mathematics classroom. The general methodology is a quantitative-experimental design; one group of students were administered a higher frequency mobile assignment prompt, a control group was administered a low frequency mobile assignment prompt and a third assigned homework in a traditional manner (in-class handouts). The three groups were matched based on equal aptitude and hence were randomly assigned either in the control or experimental groups. The findings showed that among the high frequency reminder group had increase of return rate and math achievement scores compared to the low frequency and traditional group. We underline the importance of classroom strategies in the improvement of student learning practices by engaging teacher and students with appropriate technologies. The strategies suggested in this study could be implemented in teacher daily school repertoire and could be generalizable to all schools in Qatar.
\end{abstract}

\section{Keywords}

Mobile Devices; School Assignment; Frequent Reminder; Qatar; Mathematics

\section{Introduction}

School assignment has been defined simply as a task assigned to students by school teachers that are meant to be carried out after school hours [1]. Low assignment completion is when students fail to turn assignments required of them [2]. The problem of low assignment completion appears to negatively impact student achievement. While completion might be one problem, researchers have documented students' difficulties in completion because of the lack of follow-up or teachers conveying the information in a roundabout way [2]. Students generally lose interest in assignment in 10 minutes, some students claim that "homework" is dull, boring, and a waste of time [3]. Others often are overburdened with outside school activities as work [4] or unstructured time in activities [5] and different forms of diversion as in new electronic media [6] feel the assignments are a great burden. Research has also shown that there are a number of barriers that impedes assignment completion including accurately recording them, remembering to take instructions, organizing necessary materials, post homework 
strategies as in following through and completing the work, and putting the work in a safe place [7].

Analysis of The Trends in International Mathematics and Science Study (TIMSS) survey data reported a high-performing East Asian countries and Western countries in its relation with school assignments [8]. Singling out Shanghai-China, Singapore and Japan, a positive relation was found between homework and achievement on the TIMSS math test scores for first two years secondary school students [8]. Thus, in using these technologies students will be more adept to gaining and analyzing information, taking advantage of the technological possibilities to engage in communication and school interactivity.

The available school technologies include handheld devices, such as, tablet computers, personal digital assistants, portable media players, and handheld game consoles. As mobile devices get more advanced with the development of educational applications they generally restructure and juxtapose the learning environment [9]. A general educational development worldwide has shown ways to provide the experiences through learning tasks using portable tools [10]. Many of these are mobile devices that are characterized as small devices being computers that allow students to access process information at the "palm of their hand," and embark on the use of tools at any time and any place [11]. The most significant aspect of these devices is that they are used for entertainment and could provide a means to reach students in a way that they are accustomed to [12]. According to Jonassen, Carr and Yuen [13] learning activities performed on mobile devices are flexible and interactive making it so much enjoyable for students. While youth are different than adults, the mobile telephone, has youth thrive on access and interaction [14]. One idea behind this activity is the ability to use these devices to entice students in doing their homework.

While a great deal of investment has been made to improve teacher's practices in Qatar, there have been few programs that provide professional development for teachers to improve student academic practices. While stress has been made on instructional practices, little has been invested in taking small steps to increase student learning and basic educational skills through engaging them with the new technologies. This study is one attempt to understand how engaging in mobile devices improves student study skills strategies.

\section{Objectives}

The contact of the researcher with teachers in preparatory and secondary schools informed the researcher that students were not able to keep up with needed work in the classroom particularly in applying the knowledge to specific problems and thus translate the information shared with them in class into a demonstrative learning experience. Therefore, we began conceptualizing ways new technologies can motivate students to advance organizational techniques that address school assignments. Technologies as in mobile devices allow students to engage in educational activities using what they are accustomed to, as in the smart phones to support or improve student's completion of school assignment. Thus the research question of this study: "Does changing the format of homework assignment through the use of smart phones improve student, mathematics academic outcomes whether in completion or achievement?" The main hypothesis of this study is that "mobile devices can increase the assignment completion rate and achievement of secondary school students." This proposition is based on the two main theories, the first is Bandura's Social Learning Theory which suggests that the actions of a person is strongly influenced by their consequences [15]. Namely, that students realize the effects of a performing a certain behavior, they associate the behaviors with specific and possible consequences which reinforces the source behavior. The second perspective is drawn from the theory of effect originally developed by Thorndike [16]. The theory of Law of Effect suggests that when choosing a course of action that experience gained has the least level of struggle which then reinforces the behavior based upon the consequences. Thus, by engaging students in certain behavior as in school assignment through a positive reinforcement they will more likely to continue in that behavior whereas the learner might be negatively reinforced where the interaction allows for the learner to try out different actions and causes further motivation for the student to achieve a desired goal. Thus we see the engagement of these devices as interactive and in real time have different consequences in reinforcement. Using these technologies could support teachers and reinforce positively student learning behavior. The main objective of this study is to investigate the effects of using smartphones applications to increase completion rates of assignment that could impact student achievement in mathematics.

\section{Methodology}

The study used the quantitative experimental design [17]. The study collected data to reach conclusions regard- 
ing the effective use of mobile devices in student school work. The study compares students who engage in mobile technologies with those who use the traditional classroom methods. Two groups were assigned homework through the mobile devices, the control group was assigned homework through a traditional approach.

The first steps of the study elicited information on the types of communication students used and identified students' phone devices. Specifically, the researcher surveyed whether students communicated through SMS messaging, Whatsapp, Blackberry Messenger, Viper or any other apps available on the smartphones.

Students from three section taking mathematics were assessed on a mathematics diagnostic test. The test was performed to control for any variations among student level. Once students were identified, the two groups of students were randomly assigned to two control groups and one to an experimental group. One control group known as the traditional group were given the assignment in form of handout, and a second group was informed through messaging apps (one reminder known as low frequency group). The experimental group was sent three reminders daily including weekends (known as the high frequency group). The control group was assigned homework in class through regular handouts. No verbal announcements were made in class of the homework. The students assigned to low frequency reminder control group was not assigned homework in the classroom and told that it was sent to them through a messaging system.

The duration of the study lasted for five weeks. An automated text messaging software would prompt the low and high frequency groups through SMS, a social networking systems as well as the school Learning Management System. An assignment calendar reminder was also attached as a messenger to students to help students know the current assignments, future assignments, and assignment due dates.

\subsection{Sample}

The sample included 58 secondary students recruited for this study. There were 18 students in the traditional control group, 18 in the one reminder control group and 22 in the experimental group. Students were in grade 11; the ages of the students were between 17-18 years. Students in all groups were taught by the same teacher. Students who did not have a smartphone device or tablet were lending out for the duration of the study.

\subsection{Research Site}

The research setting took place in Qatar's Independent Secondary School (public schools) that enrolls approximately 450 secondary students. The majority of the student body is Qatari. The schools attendance rate is $85.7 \%$. According to school's timetable, grade 11 has six advanced math lessons per week with 50 minutes per lesson. The total number of students in grade 11 is about 150 students. The school has a friendly atmosphere with high standards for students and staff. The researcher worked closely with the math teacher to develop the structure and interventions i.e., reminders.

\subsection{Measures and Analysis}

Two main measures included the rate-of-return of homework and the grades students received on the homework. Differences between the three groups: traditional, low frequency and high frequency reminder groups. Two main analyses were performed in this study. The first analysis involved the rate-of-return on the assignments. The second analysis involved student scores on the homework, the first analysis was descriptive and illustrative using line graphs and trend predictive lines to analyze the differences between the three groups (traditional, low frequency and high frequency). The second statistical analysis included and a Repeated Measure Analysis of Variance-Split-Plot was performed to determine the interaction within each group over a five-week period.

\section{Findings}

The first analysis reflects the difference among the three groups in terms of the assignment rate-of-return. The rate-of-return was calculated by adding the number of returns of all students in a group divided by the number of students. Figure 1, illustrates the rate-of-return across the five weeks of the study among the three groups. The short and long dashed lines are lines representing high frequency and low frequency groups respectively. The straight line represents the traditional group. In both cases, the low frequency and high frequency groups rateof-returns had a positive and increasing levels of rate-of-return. 
Table 1 reports the mean and standard deviation of the homework achievement scores for each week. Figure 2 illustrates the mean across the five periods or five weeks. It is evident from the results that the highest means appeared for those in the high frequency group. Particularly in the fifth week of the study, students in the high frequency reminder group had scored the highest in addition to highest homework return rates.

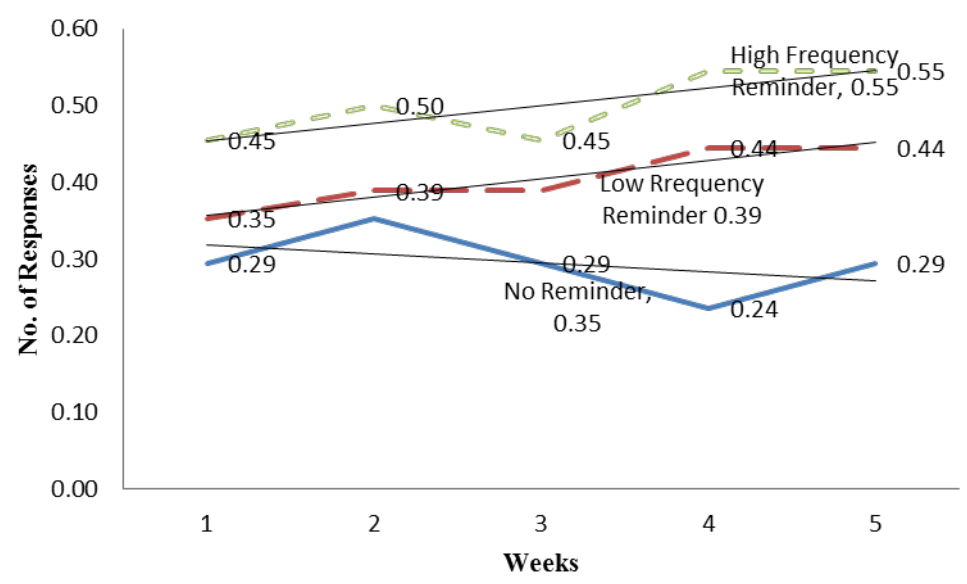

Figure 1. Distribution of homework solutions against weeks.

Table 1. Marginal mean scores for each of the conditions: traditional.

\begin{tabular}{|c|c|c|c|c|}
\hline & Group & Mean & Std. Deviation & $\mathrm{N}$ \\
\hline \multirow{4}{*}{ Week 1} & Traditional & 2.06 & 3.506 & 18 \\
\hline & Low Frequency & 1.94 & 3.539 & 18 \\
\hline & High Frequency & 3.64 & 4.170 & 22 \\
\hline & Total & 2.62 & 3.801 & 58 \\
\hline \multirow{4}{*}{ Week 2} & Traditional & 2.44 & 3.634 & 18 \\
\hline & Low Frequency & 1.83 & 2.595 & 18 \\
\hline & High Frequency & 2.64 & 3.215 & 22 \\
\hline & Total & 2.33 & 3.142 & 58 \\
\hline \multirow{4}{*}{ Week 3} & Traditional & 2.06 & 3.506 & 18 \\
\hline & Low Frequency & 3.61 & 4.692 & 18 \\
\hline & High Frequency & 3.50 & 3.997 & 22 \\
\hline & Total & 3.09 & 4.075 & 58 \\
\hline \multirow{4}{*}{ Week 4} & Traditional & 1.33 & 3.087 & 18 \\
\hline & Low Frequency & 3.17 & 3.777 & 18 \\
\hline & High Frequency & 4.27 & 4.073 & 22 \\
\hline & Total & 3.02 & 3.837 & 58 \\
\hline \multirow{4}{*}{ Week 5} & Traditional & 2.94 & 4.952 & 18 \\
\hline & Low Frequency & 4.39 & 5.112 & 18 \\
\hline & High Frequency & 5.09 & 5.013 & 22 \\
\hline & Total & 4.21 & 5.018 & 58 \\
\hline
\end{tabular}




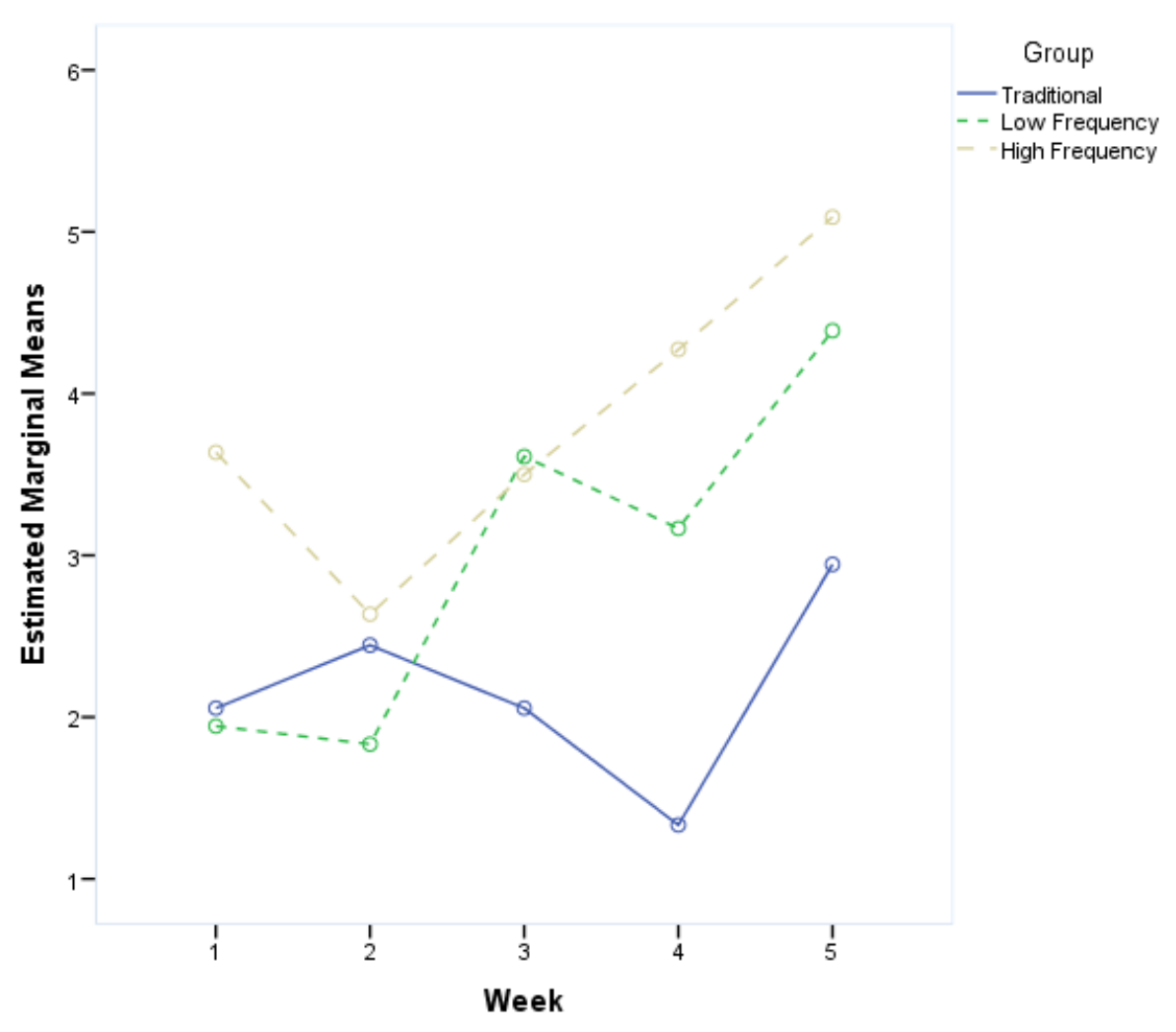

Figure 2. Marginal mean scores of homework by week.

The Repeated Measure Analysis of Variance "Split-Plot" analysis showed the three groups (traditional, low frequency and high frequency) combined increased in their homework scores across time with an $\mathrm{F}(4,220)=$ $5.42, \mathrm{p}=0.00$. The most important analysis was interaction effects between the conditions and across the five weeks. Our expectations were that the mean of the high frequency group would be significantly different than the traditional group (control group) in the fifth week of the study. The finding showed a non-significant difference with an $F(8,220)=1.58, p=0.134$. The tests between subject designs showed the difference between the three groups traditional, low frequency and high frequency was not significant at $F(2,55)=1.164 \mathrm{p}=0.00$; suggesting no difference on achievement.

\section{Conclusion and Implications}

Certainly common digital and smartphone devices offer a wide range of functionalities useful for teachers and university faculty [18]. Many of these devices equipped with $3 \mathrm{G} / 4 \mathrm{G}$, touch screen, multimedia software and Apps are carried by youth, generally replacing notebooks and pens and have similar functionalities as they take important notes, reading and receiving homework assignments [19]. Furthermore, tablets and software and communication capabilities are socially engaging in communication tool among young people [19]. The ability for these devices to be mobile has offered new teaching and learning possibilities for teachers and students [20].

In this study we examined the trends of homework return rates through comparing the three approaches to the delivery of school assignments using mobile devices. The findings showed an increase in the return rates of the homework among those in the high frequency group with a high and positive trend compared to the other two conditions in terms of rate-of-return. In terms of the achievement scores, students with high frequency reminders had scored the highest compared to the low frequency and traditional groups. Although the differences were not significant it was apparent that increasing scores with time (see fourth and fifth week). Simply getting students to continue and persist in the homework draws to achieve higher on academic tasks.

While in this study we thought to address student outcomes using mobile devices we would see that in any future research and follow-up study, a feedback application with assignment prompt through regular prompts 
should avail a richer application. The feedback to the homework will include solutions to previous homework and most common mistakes. We would also see a need for the development of the applications in these devices.

Further note, this study was carried out in Qatar, results of students on mathematics and science, international assessments outcomes have been reported to be as one of the lowest in the world and is based on the Program for International Student Assessment (PISA) [21]. This raises questions about the Qatari reform, the quality of education in Qatari schools and the role of mobile devices and mobile learning to improve the educational processes. Further, we see the need for the development of Apps by presenting a logical unit in form of applications and homework exercises with feedback and solutions.

\section{Acknowledgements}

This publication was made possible by UREP grant \# UREP 13-097-5-025 from the Qatar national research fund (a member of Qatar foundation). The statements made herein are solely the responsibility of the author(s).

\section{References}

[1] Cooper, H. (1994) Homework research and policy: A review of the literature. Research/Practice, 2. http://carei.coled.umn.edu/ResearchPractice/v2n2/homework.html

[2] Salend, S.J. and Gajria, M. (1995) Increasing the homework completion rates of students with mild disabilities. Remedial and Special Education, 16, 271-279. http://dx.doi.org/10.1177/074193259501600503

[3] Bryan, T. and Burstein, K. (2004) Teacher-selected strategies for improving homework completion. Remedial and Special Education, 19, 263-275. http://dx.doi.org/10.1177/074193259801900502

[4] Staff, J., Schulenberg, J. and Bachman, J. (2010) Adolescent work intensity, school performance, and academic engagement. Sociology of Education, 83, 183-200. http://dx.doi.org/10.1177/0038040710374585

[5] Brown, S.L., Nobiling, D.B., Teufel, J. and Birch, D.A. (2011) Are kids too busy? Early adolescents' perceptions of discretionary activities, overscheduling, and stress. Journal of School Health, 81, 574-580. http://dx.doi.org/10.1111/j.1746-1561.2011.00629.x

[6] Xu, J. and Corno, L. (2003) Family help and homework management reported by middle school students. Elementary School Journal, 103, 503-518. http://dx.doi.org/10.1086/499737

[7] Bryan, T., Burstein, K. and Bryan, J. (2001) Students with learning disabilities: Homework problems and promising practices. Educational Psychologist, 36, 167-180. http://dx.doi.org/10.1207/S15326985EP3603 3

[8] Wößmann, L. (2005) Educational production in East Asia: The impact of family background and schooling policies on student performance. German Economic Review, 6, 331-353. http://dx.doi.org/10.1111/j.1468-0475.2005.00136.x

[9] Holzinger, A., Nischelwitzer, A. and Meisenberger, M. (2005) Lifelong-learning support by m-learning: Example scenarios. eLearn, 11. http://elearnmag.acm.org/featured.cfm?aid=1125284

[10] Kukulska-Hulme, A. (2007) Mobile usability in educational contexts: What have we learnt. International Review of Research in Open and Distance Learning, $8,2$.

[11] Ching, D., Shuler, C., Lewis, A. and Levine, M.H. (2009) Harnessing the potential of mobile technologies for children and learning. In: Druin, A., Ed., Mobile technology for children: Designing for interaction and learning, Morgan Kaufmann Publishers, Amsterdam, 23-42. http://dx.doi.org/10.1016/B978-0-12-374900-0.00002-8

[12] Redd, J. (2011) Supporting vocabulary growth of high school students: An analysis of the potential of a mobile learning device and gaming app. Unpublished Doctoral Dissertation, Iowa State University, Iowa, US.

[13] Jonassen, D.H., Carr, C. and Yueh, H.P. (1998) Computers as mind tools for engaging learners in critical thinking. TechTrends, 43, 24-32. http://dx.doi.org/10.1007/BF02818172

[14] Ling, R. \& Yttri, B. (2001) Nobody sits at home and waits for the telephone to ring: Micro and hyper-coordination through the use of the mobile telephone, Perpetual Contact. Edited by Katz, J. and Aakhus, M. Cambridge University Press, Cambridge.

[15] Bandura, A. (1986) Social foundations of thought and action: A social cognitive theory. Prentice-Hall, Englewood Cliffs.

[16] Thorndike, E.L. (1905) Elements of psychology. A. G. Seiler, New York. http://dx.doi.org/10.1037/10881-000

[17] Ary, D., Jacobs, L. and Razavieh, A. (2002) Introduction to Research. 6th Edition, Wadsworth, Belmont.

[18] Csete, J., Wong, Y.H. and Vogel, D. (2004) Mobile devices in and out of the classroom. In: Cantoni, L. and McLoughlin, C., Eds., Proceedings of World Conference on Educational Multimedia, Hypermedia and Telecommunications, 
AACE, Chesapeake, 4729-4736. http://www.editlib.org/p/11746

[19] Timmermann, P. (2010) Is my iPad in my backpack? Journal of Digital Research \& Publishing. http://www.artichokewebdesign.com/ARIN6912/PDFs/Pilar Timmerman Digital Education.pdf

[20] Hutchison, A., Beschorner, B. and Schmidt-Crawford, D. (2012) Exploring the use of the iPad for literacy learning. The Reading Teacher, 66, 15-23. http://dx.doi.org/10.1002/TRTR.01090

[21] Baldi, S., Jin, Y., Skemer, M., Green, P.J. and Herget, D. (2007) Highlights from PISA 2006: Performance of US 15-year-old students in science and mathematics literacy in an international context (NCES 2008-016). National Center for Education Statistics, Institute of Education Sciences, US Department of Education, Washington DC. 